\title{
Quantification of octacalcium phosphate, authigenic apatite and detrital apatite in coastal sediments using differential dissolution and standard addition
}

\author{
J. F. Oxmann ${ }^{1, *}$ and L. Schwendenmann ${ }^{1}$ \\ ${ }^{1}$ School of Environment, The University of Auckland, Auckland 1010, New Zealand \\ * currently at: GEOMAR Helmholtz Centre for Ocean Research Kiel, Marine Biogeochemistry, 24148 Kiel, Germany
}

Correspondence to: J. F. Oxmann (joxmann@geomar.de)

Received: 4 January 2014 - Published in Ocean Sci. Discuss.: 31 January 2014

Revised: 20 May 2014 - Accepted: 21 May 2014 - Published: 30 June 2014

\begin{abstract}
Knowledge of calcium phosphate (Ca-P) solubility is crucial for understanding temporal and spatial variations of phosphorus (P) concentrations in water bodies and sedimentary reservoirs. In situ relationships between liquid- and solid-phase levels cannot be fully explained by dissolved analytes alone and need to be verified by determining particular sediment $\mathrm{P}$ species. Lack of quantification methods for these species limits the knowledge of the $\mathrm{P}$ cycle. To address this issue, we (i) optimized a specifically developed conversion-extraction (CONVEX) method for $\mathrm{P}$ species quantification using standard additions, and (ii) simultaneously determined solubilities of $\mathrm{Ca}-\mathrm{P}$ standards by measuring their $\mathrm{pH}$-dependent contents in the sediment matrix. Ca-P minerals including various carbonate fluorapatite (CFAP) specimens from different localities, fluorapatite (FAP), fish bone apatite, synthetic hydroxylapatite (HAP) and octacalcium phosphate (OCP) were characterized by XRD, Raman, FTIR and elemental analysis. Sediment samples were incubated with and without these reference minerals and then sequentially extracted to quantify $\mathrm{Ca}-\mathrm{P}$ species by their differential dissolution at $\mathrm{pH}$ values between 3 and 8 . The quantification of solid-phase phosphates at varying $\mathrm{pH}$ revealed solubilities in the following order: $\mathrm{OCP}>\mathrm{HAP}>\operatorname{CFAP}\left(4.5 \% \mathrm{CO}_{3}\right)>\operatorname{CFAP}(3.4 \%$ $\left.\mathrm{CO}_{3}\right)>\operatorname{CFAP}\left(2.2 \% \mathrm{CO}_{3}\right)>$ FAP. Thus, CFAP was less soluble in sediment than HAP, and CFAP solubility increased with carbonate content. Unspiked sediment analyses together with standard addition analyses indicated consistent differential dissolution of natural sediment species vs. added reference species and therefore verified the applicability of the CONVEX method in separately determining the most
\end{abstract}

prevalent $\mathrm{Ca}-\mathrm{P}$ minerals. We found surprisingly high OCP contents in the coastal sediments analyzed, which supports the hypothesis of apatite formation by an OCP precursor mechanism.

\section{Introduction}

Phosphorus cycles are influenced by $\mathrm{P}$ concentration and composition in both the liquid and solid phase. Although non-equilibrium behaviour is typical for natural systems (Carman and Rahm, 1997), precipitation and dissolution mechanisms may occasionally attain equilibrium between certain P minerals and dissolved inorganic P (DIP). Provided DIP levels are controlled by these mechanisms, $\mathrm{P}$ minerals may be qualitatively determined in natural (Avnimelech, 1983; Bray et al., 1973; Emerson and Widmer, 1978; Gaudette and Lyons, 1980) or experimental (Murrmann and Peech, 1969; Oxmann et al., 2008) environments using appropriate dissociation constants and apparent solubility products allowing for ionic strength effects and ion-pairing. Identification of particular mineral species using solubility criteria is, however, seldom reported for natural systems, mainly due to kinetic control of mineral reactions and/or adsorptioncontrolled DIP levels. For instance, $\mathrm{P}$ may be sorbed to $\mathrm{Fe}, \mathrm{Al}$ and Mn oxides, iron oxyhydroxides, kaolinite and montmorillonite (Bar-Yosef et al., 1988; Chen et al., 1973; Hutchison and Hesterberg, 2004; Parfitt et al., 1975).

Whether adsorption effects or mineral formation and dissolution influence soluble $\mathrm{P}$ concentrations depends largely on sediment types and physical-chemical conditions. For 
example, the redox state affects DIP by promoting sorption to a $\mathrm{FeOOH}$-phosphate complex in oxic sediments and release from this complex under reducing conditions (Einsele, 1936; Mortimer, 1941). A decrease of the redox potential (Eh) may therefore release $\mathrm{P}$ and could cause a shift from sorption to precipitation (Mortimer, 1971; Ruttenberg and Berner, 1993). However, soil incubation experiments by Murrmann and Peech (1969) indicated that $\mathrm{pH}$ also significantly affects adsorption-desorption and precipitation-dissolution mechanisms: whereas DIP was controlled by sorption below $\mathrm{pH}$ values of 8 , DIP was in equilibrium with octacalcium phosphate (OCP) above $\mathrm{pH}$ 8. A similar $\mathrm{pH}$-mediated change from adsorption to precipitation was confirmed for coastal sediments (Oxmann et al., 2008) and agrees with a reduced sorption capacity by (hydr)oxide minerals with increasing pH (Oh et al., 1999; Spiteri et al., 2008; Barrow et al., 1980; Naidu et al., 1990) and lower OCP solubility under progressively increasing alkaline conditions (Fig. 1; Lindsay et al., 1989). Hence, pH- and Eh-mediated effects are difficult to separate. Phosphorus release during reduction could also be caused by apatite solubilization (Golterman, 2001) because a change to anoxic conditions is often accompanied by pore water acidification (Jourabchi et al., 2005).

Due to decreasing apatite solubility with decreasing acidity (Fig. 1), calcium phosphate (Ca-P) concentrations of soils and sediments generally increase with $\mathrm{pH}$ (Lindsay et al., 1989; Oxmann et al., 2010; Tyler, 2002). Accordingly apatite frequently constitutes the main $\mathrm{P}$ fraction of marine sediments (e.g. Daesslé et al., 2004; Morse and Cook, 1978). Apatite is classified into biogenic and inorganic apatite. The formation of inorganic apatite by chemical precipitation and recrystallization processes has been subject of extensive research during past decades (e.g. Bentor, 1980; Sheldon, 1981; Tribble et al., 1995). Earlier research focused on the formation of carbonate fluorapatite (CFAP) bearing phosphorite deposits, which are referred to as such if they contain more than $5 \mathrm{wt} \% \mathrm{P}_{2} \mathrm{O}_{5}$ (Ruttenberg and Berner, 1993). Phosphorites form mainly at continental shelves and have been therefore closely linked to upwelling phenomena (e.g. Kazakov, 1937; Parrish et al., 1986). Locally occurring saturation states that support a sustained CFAP precipitation were either explained by physical-chemical mechanisms, such as steady P supply by nutrient-rich deep ocean waters as well as temperature increase, pressure decrease, $p \mathrm{CO}_{2}$ decrease and $\mathrm{pH}$ increase of ascending waters (Atlas, 1975) or by biochemical processes including the high productivity at upwelling zones and related $\mathrm{P}$ enrichment of interstitial waters. Concentrations of DIP may further increase due to additional diagenetic transformations such as $\mathrm{P}$ fixation in oxic and subsequent release in anoxic sediment (Ruttenberg and Berner, 1993). Even more factors, partly independent of upwelling processes, have been proposed for the concentration of pore water phosphate, such as river sources (e.g. Pevear, 1966) and P release by sulfur bacteria (Crosby and Bailey, 2012; Schulz and Schulz, 2005). Hence, different P enrichment

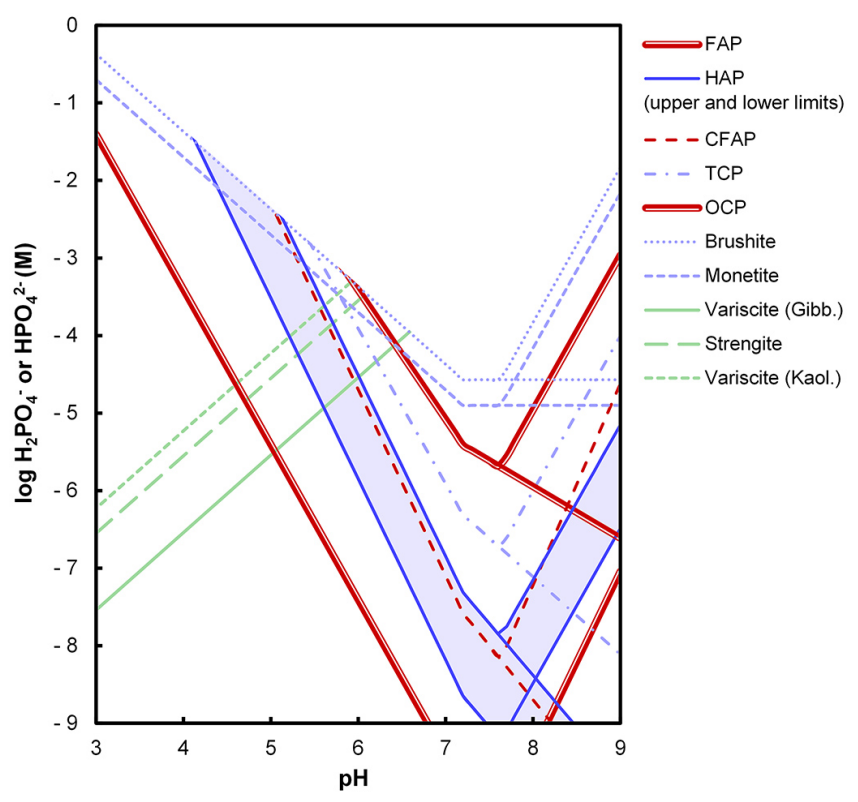

Figure 1. Apparent solubilities of calcium phosphates, strengite and variscite (in equilibrium with gibbsite or kaolinite) when $\mathrm{Ca}^{2+}$ is $10^{-2} \mathrm{M}$ or is fixed by calcite. $\mathrm{CO}_{2}(\mathrm{~g}): 0.0003 \mathrm{~atm} ; \mathrm{F}^{-}: 10^{-4} \mathrm{M}$ (equilibrium level of $\left.\mathrm{CaF}_{2}\right) ; \mathrm{CO}_{3}^{2-}$ at the given $\mathrm{CO}_{2}(\mathrm{~g})$. Strengite and variscite are more insoluble under acidic conditions while calcium phosphate solubility decreases with increasing $\mathrm{pH}$. At $\mathrm{pH}>7.88$ calcium phosphate solubility may increase due to $\mathrm{Ca}^{2+}$ depression caused by decreasing calcite solubility (see dividing curves at this $\mathrm{pH}$ for $\mathrm{Ca}^{2+}$ depression or maintained $\mathrm{Ca}^{2+}$ concentration). Calculations used apparent dissociation constants and thermodynamic solubility products reported in Lindsay et al. (1989). To exemplify the inherent uncertainties arising from variability among Ksp measurements, hydroxylapatite (HAP) solubility was calculated using the range of corresponding Ksp values reported in the literature (Baker et al., 1998). The solubility of carbonate fluorapatite (CFAP) was calculated using the apparent Ksp of $10^{-103}$ given by Perrone et al. (2002). See Lindsay et al. (1989) for details on calculations. Results for this system are similar to those computed by more-sophisticated algorithms (e.g. MEDUSA; Puigdomenech, 2000). See Atlas (1975) for the theoretical dependence of calcium phosphate solubility on salinity. FAP: fluorapatite; TCP: tricalcium phosphate; OCP: octacalcium phosphate.

mechanisms may increase the saturation state enough to enable spontaneous Ca-P precipitation for subsequent CFAP formation. However, the $\mathrm{P}$ precipitation in itself is chemically driven by the saturation state and kinetic factors without direct cellular control (e.g. Krajewski et al., 1994).

Solubility of CFAP is affected by the extent of carbonate inclusion in the crystal lattice and increases with carbonate content (Chen et al., 1973; Jahnke, 1984; LeGeros and LeGeros, 1984). Due to its extensive distribution in common sediments or deposits, CFAP has been suggested to be an important oceanic sink of reactive $P$ (Ruttenberg, 1992; Ruttenberg and Berner, 1993). While numerous studies suggested that seawater is largely CFAP undersaturated despite the 
extensive CFAP distribution (Baturin, 1981; Bentor, 1980, and references therein), Atlas and Pytkowicz (1977) and Sheldon (1981) argued that seawater is close to CFAP saturation but noted the extremely slow kinetics of homo- or hetero-nucleation observed by incubation experiments. According to these kinetic considerations, Ca-P precipitation is apparently prevented in the water column (Atlas, 1975; Atlas and Pytkowicz, 1977). Moreover, direct nucleation of apatite was found to be inhibited by magnesium and, thus, spontaneous inorganic precipitation suggested to be kinetically impossible in marine environments (Golubev et al., 1999; Gunnars et al., 2004; Martens and Harriss, 1970). In contrast, magnesium has a lesser inhibitory effect on the precipitation of more soluble precursor phases and therefore selectively stabilizes precursor phases (Gunnars et al., 2004; Johnsson and Nancollas, 1992).

Given the kinetic constraints of apatite nucleation under supersaturated conditions, more soluble $\mathrm{Ca}-\mathrm{P}$ species may affect apatite formation according to the Ostwald step rule (Morse and Casey, 1988; Nancollas et al., 1989). Thus other Ca-P minerals, such as OCP and amorphous calcium phosphate (ACP), may represent significant sinks during early diagenesis and may influence soluble P levels. Incubation experiments with seawater indicated apatite formation by prior precipitation of metastable precursor phases, and a corresponding mechanism has been suggested for certain phosphorite deposits (Gunnars et al., 2004; Jahnke et al., 1983; Krajewski et al., 1994; Van Cappellen and Berner, 1988; Schenau et al., 2000). Apatite precursors are however difficult to identify, even in relatively simple mixtures without interfering sample matrices. Therefore, direct evidence for the sedimentary occurrence of OCP or ACP is scarce owing to methodological issues with respect to complex matrices.

Phosphorus analysis in sediment is generally performed by sequential extraction methods, which mainly separate the following $\mathrm{P}$ fractions: (i) exchangeable or loosely sorbed $\mathrm{P}$, (ii) $\mathrm{Al} / \mathrm{Fe}-$ bound $\mathrm{P}$ ( $\mathrm{Al} / \mathrm{Fe}-\mathrm{P}$ ), (iii) $\mathrm{Ca}-\mathrm{P}$, and (iv) organic P. Sequential extraction methods were developed for agricultural purposes (e.g. Hedley et al., 1982) and subsequently modified for sedimentary studies (e.g. SEDEX method, Ruttenberg, 1992). Phosphorus fractions were subdivided in some schemes in order to yield additional pools, such as CFAP (Ruttenberg, 1992) and Al-P (Kuo, 1996). To support the interpretation of these widely used extraction methods a complementary speciation method was recently developed to quantify OCP and different apatites (CONVEX; Fig. 2; Oxmann et al., 2008). This method combines a conversion of $\mathrm{P}$ compounds by batch titration with subsequent sequential extraction and was proposed to be used together with conventional methods.

To validate the specificity of the CONVEX method, Oxmann et al. (2008) conducted standard addition experiments using OCP, hydroxylapatite (HAP), strengite and variscite. For Ca-P, addition experiments revealed that OCP can be well distinguished from apatites due to its significantly higher solubility (Oxmann et al., 2008). Using CONVEX, we found that OCP was the major Ca-P species in alkaline sediments (Oxmann et al., 2008). Added HAP dissolved at lower $\mathrm{pH}$ and a third distinguishable compound dissolved upon further acidification. The latter was not identified due to lack of available standards but suggested to be fluorapatite (FAP). Carbonate fluorapatite remained also unverified by addition experiments despite its relevance. Theoretically, CFAP may be more or less soluble than HAP based on the apparent solubility product of Perrone et al. (2002; see Fig. 1). To demonstrate the applicability of the CONVEX method, especially for purposes of marine Ca-P analyses, we provide supplementary standardization by addition experiments in this study and show appropriate selective dissolution.

Our specific objectives were (i) to validate the specificity of the CONVEX method for FAP and CFAP, and (ii) to verify consistent differential dissolution of natural sedimentary species vs. added reference species. At the same time, this method refinement allowed for (i) a comparison of $P$ species in similar sediments of temperate and tropical tidal flats in order to test cross-regional transferability, and (ii) an analysis of Ca-P solubilities in sediment including effects of mineral carbonate content on dissolution. Because CFAP is one of the most important species for marine $\mathrm{P}$ cycling and its solubility is largely unknown due to varying carbonate inclusion and incongruent dissolution (e.g. Perrone et al., 2002), we focused on an extended CFAP standard set from different localities.

\section{Materials and methods}

\subsection{Sediment sampling, preparation and characterization}

A sediment core was taken in a temperate tidal flat (Firth of Thames, New Zealand) using a polycarbonate corer (length $45 \mathrm{~cm}$; diameter $9 \mathrm{~cm}$ ). The sampling location (lat. $-37.21321^{\circ}$, long. $175.38854^{\circ}$ ) was $180 \mathrm{~m}$ from the mangrove fringe and had an inundation duration of 130 days per year corresponding to a height of $67 \mathrm{~cm}$ above m.s.l. (mean sea level).

Sediment redox potential (Eh), $\mathrm{pH}$ and temperature were determined in situ at $5 \mathrm{~cm}$ intervals (sulfide resistant, sludge suitable SensoLyt SEA/PtA electrodes; Pt-100 temperature sensor; pH/Cond340i; pH 3310; WTW, Weilheim, Germany). Sensors were inserted through sealable corer inlets and connected to a computer using optoisolators (USBisolator; Serial: 289554B; Acromag Inc., MI, USA). Data were recorded using the software MultiLab pilot (WTW, Weilheim, Germany) to determine final measurement values. Sediment from $30-35 \mathrm{~cm}$ was selected for subsequent analyses as this layer was less affected by tidal changes, runoff or bioturbation. Field moist subsamples were taken for salinity determination (wet sediment to deionized water 
ratio - 1:5; TetraCon 325 electrode; WTW, Weilheim, Germany) and for particle size measurement using laser diffractometry (sediment dispersed in $10 \%$ sodium hexametaphosphate solution; Mastersizer 2000; Malvern Instruments Ltd., Malvern, UK). The remaining part of the sample was dried at $37^{\circ} \mathrm{C}$, ground with a planetary mill ( $<300 \mu \mathrm{m}$ mesh; PM 100; Retsch, Haan, Germany) and used for subsequent conversion-extraction analyses (see CONVEX method: Sect. 2.4). Basic P fractionation into $\mathrm{Al} / \mathrm{Fe}-\mathrm{P}$ and Ca-P was carried out according to Kurmies (1972) with minor modifications as described in Oxmann et al. (2008).

With an Eh of $-98 \mathrm{mV}$ and a $\mathrm{pH}$ of 7.467 , the sediment was reduced and slightly alkaline and had clay, silt and sand fractions of 8,34 and 58\%, respectively. Calcium phosphate bound $\mathrm{P}$ was the predominant fraction with

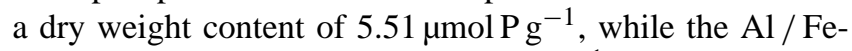
$\mathrm{P}$ pool had an amount of $3.02 \mu \mathrm{mol} \mathrm{Pg}{ }^{-1}$. Sediment moisture content was $58 \%$ and salt concentration was $16.5 \%$. Results of CONVEX analysis of the sediment from the Firth of Thames were compared with those of tidal flat sediment from the Saigon River delta (Ca-P: $5.36 \mu \mathrm{mol} \mathrm{P} \mathrm{g}^{-1}$; $\mathrm{Al} / \mathrm{Fe}-$ P: $5.90 \mu \mathrm{mol} \mathrm{Pg}^{-1}$; pH: 7.47 ; clay: $12 \%$, silt: $83 \%$; sand: $5 \%$; Oxmann et al., 2008) to test cross-regional transferability (see Sect. 3.1).

\subsection{Preparation and identification of calcium phosphate reference minerals}

In total, eleven Ca-P minerals were prepared for standard addition experiments. Their origin is given in Table 1. Specimens were acquired from mineral distributors, synthetic HAP was purchased from Sigma Aldrich (St. Louis, Missouri, USA) and OCP was synthesized as described in Christoffersen et al. (1990).

A large single FAP crystal was ground to powder and used without further preparation. All CFAP specimens with visually distinguishable mineral attachments had characteristics of either (i) numerous small needle-like or small hexagonal crystals attached to a matrix, or (ii) spheres of a botryoidal cluster embedded into a matrix (Table 1). To generate pure mineral samples, crystals were picked and spheres were isolated from the matrix under a binocular microscope. Received fragments were again inspected to avoid any significant contamination and subsequently ground. Cryptocrystalline collophane could not be purified and in this case the entire specimen was ground. Correspondingly, all bones of a fresh Australasian snapper (Pagrus auratus) were ground after they were cleaned from attached tissue with a knife and dried at $40^{\circ} \mathrm{C}$. Heating at elevated temperatures, boiling in water or chemical clean-up was avoided to prevent changes to the crystalline structure or carbonate content. Because collophane and bone specimens were not purified, their carbonate content was not determined. In contrast, care was taken during purification of other samples for precise quantification of their mineral carbonate content.

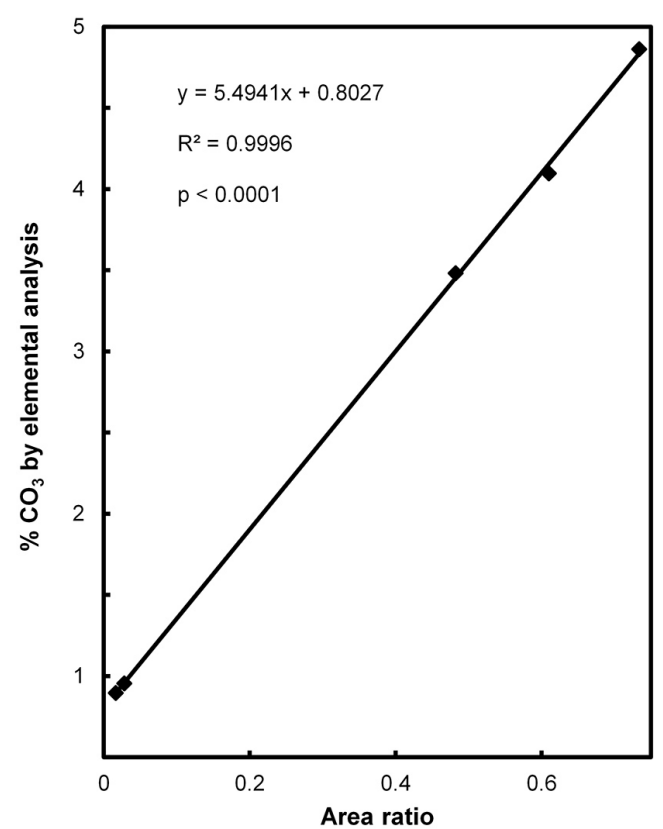

Figure 2. FTIR calibration for carbonate content determination of calcium phosphate minerals. Ratio of the extinction of the FTIR carbonate band to phosphate band (areas, $E_{\left.1380-1440 / E_{550-590}\right)}$ vs. carbonate content (\% by weight) determined by elemental analysis. For calibration, data of five minerals with known $\mathrm{CO}_{3}$ content were used (cf. Table 1, minerals with performed elemental analysis). Contents of other minerals listed in Table 1 were calculated using the indicated correlation (method after Featherstone et al., 1984 with modification).

Mineral analyses were performed using X-ray diffraction (XRD; PW 1130 HV generator; automation-modified 1050/25 goniometer fitted with PW 1752 curved graphite crystal monochromator and PW 1965 proportional detector; Philips Analytical, Amsterdam, the Netherlands; $\mathrm{Cu}-$ tube, $40 \mathrm{kV}, 20 \mathrm{~mA}$ ), Raman spectroscopy (RM1000 confocal micro-Raman system; Renishaw, Gloucestershire, UK; laser excitation at $488 \mathrm{~nm}, 26 \mathrm{~mW}$ ) and Fourier transform infrared spectroscopy (FTIR; Spectrum One FT-IR Spectrometer; Perkin Elmer, MA, USA; $4 \mathrm{~cm}^{-1}$ spectral resolution). Synthesized OCP was additionally confirmed using X-ray absorption near-edge structure spectroscopy (XANES; P Kedge; see Oxmann, 2014; spectrum collected by Kruse et al., 2010). Briefly, crystals and spheres were pure, highly crystalline and correctly identified. In contrast, snapper bones and collophane were found to be impure and less crystalline. Despite impurities, both samples had relatively high $\mathrm{P}$ contents. Snapper bone contained more than $50 \%$ of the P content of pure minerals and collophane approximately five-fold less than pure minerals as determined by photometric determination (see Sect. 2.4). 
Table 1. Basic properties, performed analyses and carbonate content (\% by weight) of Ca-P reference minerals used for standard addition experiments.

\begin{tabular}{|c|c|c|c|c|c|}
\hline ID-Mineral $^{\mathrm{a}}$ & Origin & Type/appearance & Characterization & Purity ${ }^{b}$ & $\mathrm{CO}_{3}$ \\
\hline MS-CFAP & Moculta Phosphate Quarry, Angaston, Australia & Var. Staffelite, botryoidal, yellow-brown & XRD, FTIR, Raman, EA & PS & 4.4 \\
\hline MS-CFAP & Staffel, Limburg, Germany & Var. Staffelite, botryoidal, brown & XRD, FTIR, Raman, EA & PS & 4.7 \\
\hline KC-CFAP & Zheleznyi Mine, Kola Peninsula, Russia & Var. Staffelite, botryoidal, blue-green & XRD, FTIR, Raman, EA & PS & 3.4 \\
\hline KC-CFAP & Holmbush Mine, Callington, Cornwall, UK & Var. Holmbushite, needle-like crystals & XRD, FTIR, Raman & $\mathrm{PC}$ & 3.4 \\
\hline CW-CFAP & Geevor Mine, Pendeen, Cornwall, UK & Small hexagonal crystals, brown & XRD, FTIR, Raman & $\mathrm{PC}$ & 2.3 \\
\hline CW-CFAP & Levant Mine, Pendeen, Cornwall, UK & Small hexagonal crystals, brown & XRD, FTIR, Raman & $\mathrm{PC}$ & 2.1 \\
\hline BL-CFAP & Bonny Lake, Florida, USA (with HAP and FAP) & Var. Collophane, cryptocrystalline & XRD, FTIR, Raman & BS & ND \\
\hline DU-FAP & Cerro de Mercado Mine, Durango, Mexico & Single large hexagonal crystal, green & XRD, FTIR, Raman, EA & $\mathrm{PC}$ & 1.0 \\
\hline SB-AP & Pagrus auratus bones, New Zealand & Nanocrystalline apatite inclusion & XRD, FTIR, Raman & BS & ND \\
\hline ST-HAP & Synthetic & Crystalline powder & XRD, FTIR, Raman, EA & $\mathrm{S}$ & 0.9 \\
\hline ST-OCP & Synthetic & Crystalline powder & XRD, FTIR, Raman, XANES & $\mathrm{S}$ & 0.8 \\
\hline
\end{tabular}

\subsection{Carbonate content of Ca-P reference minerals}

In order to determine mineral carbonate content, FTIR and elemental analysis were used. Calibration of FTIR by apatite samples with known carbonate contents is an accurate method for carbonate quantification, which uses the extinction ratio of the FTIR carbonate to phosphate band. For FTIR, $2 \mathrm{mg}$ of sample was ground with $200 \mathrm{mg}$ of potassium bromide and pressed in a mechanical press to form pellets for spectroscopy. Analysis was carried out as described by Featherstone et al. (1984) with two modifications: (i) carbonate contents of apatite reference samples were determined using an elemental analyzer (TruSpec CNS; LECO Corp., MI, USA) instead of preparing blended apatite standards with barium carbonate, and (ii) area ratios $\left(E_{1380-1440} / E_{550-590}\right.$; Omnic Software Suite; Thermo Scientific, MA, USA) were used instead of extinction ratios at specific wave lengths. For extinction ratio calibration, data of five minerals with known carbonate content were used (cf. Table 1). Contents of other minerals listed in Table 1 were calculated using the correlation given in Fig. 2.

Results of elemental analysis correlated with those of FTIR at a significance level of 0.0001 . Hexagonal crystals from the UK had lowest carbonate contents and spheres of botryoidal clusters from Germany and Australia had highest contents (Table 1). Carbonate contents of natural FAP, purchased HAP and synthesized OCP were comparable and much lower than those of natural CFAP (Table 1). To verify the effect of mineral carbonate content on sedimentary CFAP solubility by a lower number of addition experiments, CFAP samples were partly pooled, excluding collophane. The upper six CFAP samples in Table 1 were pooled into three composite samples according to similar $\mathrm{CO}_{3}$ inclusions of each pooled pair (4.4 and $4.7 \%$; 3.4 and $3.4 \% ; 2.1$ and $2.3 \%$ ).

\subsection{CONVEX method}

The CONVEX method is shown in Fig. 3. For the conversion procedure $(1 \mathrm{~A} / 1 \mathrm{~B})$, sediment subsamples of $1 \mathrm{~g}$ were incubated for seven days in $10 \mathrm{~mL}$ pH-adjusted $0.01 \mathrm{M} \mathrm{CaCl}_{2}$ using two wash steps with $0.01 \mathrm{M} \mathrm{CaCl}_{2}$ after two days. Subsequently, subsamples were centrifuged and $\mathrm{pH}$ was measured in the clear supernatant solution with the instrumental set-up described above but using an InLab Micro electrode (Mettler Toledo GmbH, Greifensee, Switzerland). Soluble $\mathrm{P}$ analyses of supernatant solutions were not performed because corresponding DIP concentrations were already shown (i) to alter with $\mathrm{pH}$ in a typical manner for different sediment and soil types, (ii) to vary inversely with total inorganic $\mathrm{P}$, and (iii) to be insignificant with respect to solid-phase levels within a certain $\mathrm{pH}$ range despite large $\mathrm{P}$ transfers between Al / Fe-P and Ca-P (see Murrmann and Peech, 1969; Oxmann et al., 2008; and Sect. 3.5). For sequential extraction, dried sediment pellets were extracted by a series of steps (2A-3C) that enable an accurate separation of inorganic $\mathrm{P}$ into $\mathrm{Al} / \mathrm{Fe}-\mathrm{P}$ (mineral and adsorbed $\mathrm{P}$ ) and $\mathrm{Ca}-\mathrm{P}$ (mineral and residual $\mathrm{P}$ ). Total inorganic $\mathrm{P}$ was calculated by summing $\mathrm{Al} / \mathrm{Fe}-\mathrm{P}$ and Ca-P. Sediment subsamples without prior incubation served as controls while differences between spiked and unspiked incubations yielded $\mathrm{pH}$-dependent losses for each added standard mineral.

For addition experiments, minerals were weighed into small polyethylene caps using an ultra-micro balance (XP6U; Mettler Toledo GmbH, Greifensee, Switzerland) and then added to the sediment subsamples before incubation. The separate addition ensured homogeneity of added $\mathrm{P}$ among subsamples as opposed to a possible mineral addition to a larger sediment amount before subsample weighing. Care was taken to maintain experimental conditions and to minimize sample loss during centrifugation and decanting steps. For example, tubes were briefly centrifuged ( $3 \mathrm{~min}$, $3000 \mathrm{~g}$ ) and shaken once before each centrifugation step $(15 \mathrm{~min}, 3000 \mathrm{~g})$ in order to remove remaining particles from 


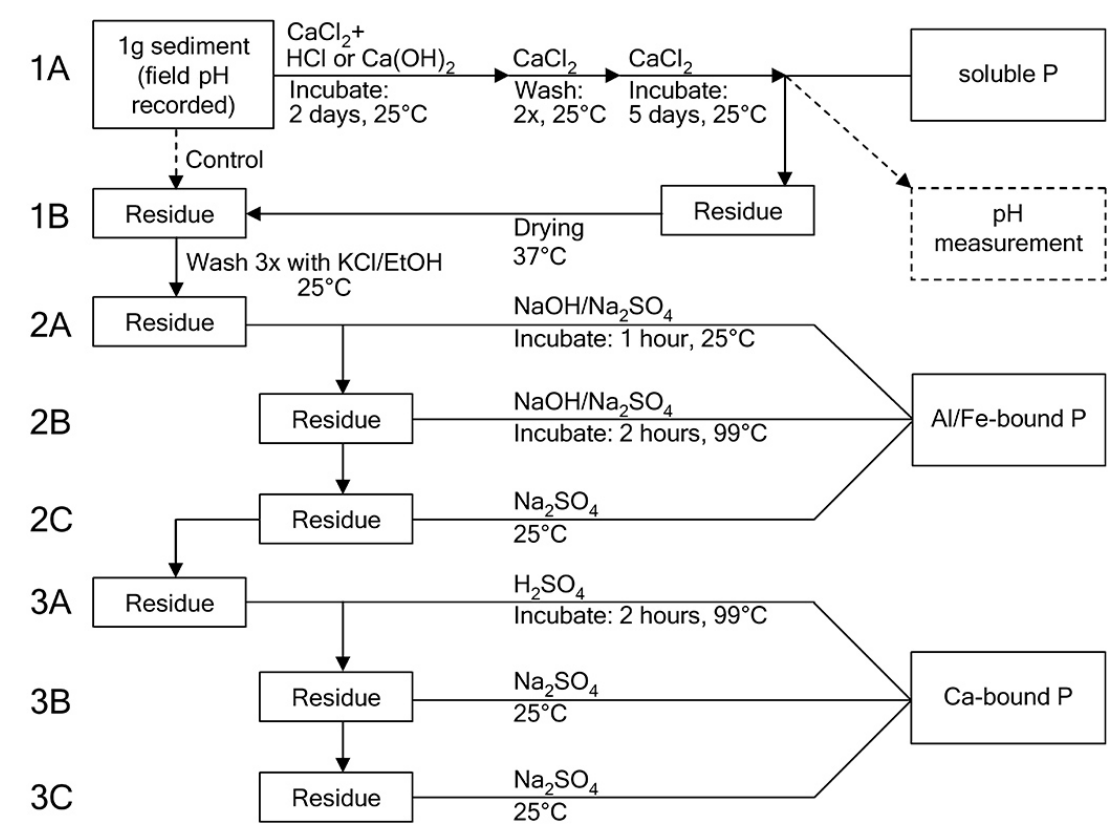

Figure 3. CONVEX scheme for the quantification of phosphorus species in sediment. 1A/1B: conversion procedure, $2 \mathrm{~A}-3 \mathrm{C}$ : extraction procedure. For addition experiments, reference minerals were added to the sediment subsamples before incubation. Adapted from Oxmann et al. (2008).

tube walls with clean supernatant solution. This procedure ensured minimal loss by subsequent decanting. Phosphate concentrations in solutions obtained by sequential extraction were determined according to Murphy and Riley (1962) using a UV-Vis spectrophotometer (Cintra 2020; GBC Scientific Equipment, Dandenong, Australia). A detailed description of the CONVEX method is given in Oxmann et al. (2008).

\subsection{Data analysis}

To quantify mineral loss for all standard addition experiments at equal $\mathrm{pH}$ values, data sets for $\mathrm{Ca}-\mathrm{P}$ vs. $\mathrm{pH}$ were interpolated $(0.001 \mathrm{pH}$ intervals) using piece-wise cubic hermite interpolating polynomial (Octave, version 3.2.4; Eaton et al., 2008). Based on maximum changes in curve slopes $(\Delta c / \Delta \mathrm{pH})$ for unspiked sediment (Sect. 3.2), differential dissolution of sediment FAP, CFAP and OCP occurred at $\mathrm{pH}$ ranges of ca. 3.0-3.5, 3.5-7.0 and 7.0-8.1, respectively. Selective losses of sediment species (sediment FAP, CFAP, OCP) and total species (added species plus corresponding sediment species) at different $\mathrm{pH}$ values were calculated according to

$\Delta c_{\text {loss }}=\Delta c_{\text {initial }}-\Delta c_{\text {actual }}$,

where $\Delta c_{\text {initial }}$ (initial concentration of each species) equals the difference between Ca-P concentrations at the beginning (upper cutoff $\mathrm{pH}$ values of 3.5, 7.0 and 8.1 for FAP, CFAP and OCP) and end (lower cutoff $\mathrm{pH}$ values of 3.0, 3.5 and 7.0 for FAP, CFAP and OCP) of each selective loss, and $\Delta c_{\text {actual }}$ (actual concentration of each species after acidification-induced losses; actual $\mathrm{pH}<$ upper cutoff $\mathrm{pH}$ ) equals the difference between Ca-P concentrations at actual and lower cutoff $\mathrm{pH}$ values (see example of calculation for OCP loss at pH 7.5 in Fig. 5a). For calculation of selective losses of added reference species (FAP, CFAP, OCP), $\Delta c_{\text {initial }}$ and $\Delta c_{\text {actual }}$ were defined by the difference between $\mathrm{Ca}-\mathrm{P}$ concentrations of spiked and unspiked incubations at upper cutoff $\mathrm{pH}$ values and actual $\mathrm{pH}$ values. The difference in Ca-P content $\left(\Delta c_{\text {initial }}\right)$ between spiked and unspiked incubations at upper cutoff $\mathrm{pH}$ values of 3.5, 7.0 and 8.1 for FAP, CFAP and OCP (average of $2.04 \mu \mathrm{mol} \mathrm{P} \mathrm{g}^{-1}$, relative standard deviation of $3.1 \%$ ) closely matched the quantity of spiked $\mathrm{P}\left(2 \mu \mathrm{mol} \mathrm{P} \mathrm{g}^{-1}\right)$ for each addition experiment. Hence, added FAP, CFAP and OCP were not significantly dissolved during incubations at $\mathrm{pH}$ values of 3.5, 7.0 and 8.1, respectively, and were quantitatively recovered by the Ca-P fraction at these $\mathrm{pH}$ values. Results from Eq. (1) were subsequently used to calculate loss percentages of sediment species, of total species and of added reference species for different $\mathrm{pH}$ values (Table 2). Based on results of standard addition experiments a slightly lower final $\mathrm{pH}$ (6.9) was preferable to calculate OCP contents (see Sect. 3.3). 
Table 2. Loss (\%) of added reference species (FAP, CFAP, OCP), total species (added species plus corresponding sedimentary species) and sedimentary species (sediment FAP, CFAP, OCP) at varying $\mathrm{pH}$ as determined by the CONVEX method. See Table 1 for abbreviations of added standard minerals.

\begin{tabular}{|c|c|c|c|c|c|c|c|c|c|c|c|}
\hline $\begin{array}{r}\text { Final } \\
\mathrm{pH}\end{array}$ & DU-FAP & $\begin{array}{r}\text { Total } \\
\text { FAP }\end{array}$ & $\begin{array}{r}\text { Sediment } \\
\text { FAP }\end{array}$ & MS-CFAP & KC-CFAP & CW-CFAP & $\begin{array}{r}\text { Total } \\
\text { CFAP }\end{array}$ & $\begin{array}{r}\text { Sediment } \\
\text { CFAP }\end{array}$ & ST-OCP & $\begin{array}{l}\text { Total } \\
\text { OCP }\end{array}$ & $\begin{array}{r}\text { Sediment } \\
\text { OCP }\end{array}$ \\
\hline 3.0 & 98 & 99 & 100 & & & & & & & & \\
\hline 3.2 & 40 & 48 & 76 & & & & & & & & \\
\hline 3.5 & 0 & 0 & 0 & 94 & 91 & 84 & 96 & 100 & & & \\
\hline 4.0 & & & & 79 & 55 & 40 & 70 & 82 & & & \\
\hline 4.5 & & & & 47 & 32 & 21 & 53 & 70 & & & \\
\hline 5.0 & & & & 31 & 23 & 18 & 43 & 58 & & & \\
\hline 5.5 & & & & 18 & 19 & 16 & 32 & 43 & & & \\
\hline 6.0 & & & & 8 & 10 & 15 & 20 & 27 & & & \\
\hline 6.5 & & & & 2 & 6 & 13 & 10 & 14 & & & \\
\hline 6.8 & & & & 1 & 4 & 8 & 6 & 7 & & & \\
\hline 6.9 & & & & 0 & 3 & 5 & 4 & 4 & 90 & 98 & $105^{b}$ \\
\hline 7.0 & & & & 0 & 0 & 0 & 0 & 0 & 81 & 91 & 100 \\
\hline 7.1 & & & & & & & & & 68 & 78 & 88 \\
\hline 7.5 & & & & & & & & & 35 & 28 & 20 \\
\hline 8.0 & & & & & & & & & 6 & 3 & 0 \\
\hline 8.1 & & & & & & & & & 0 & 0 & 0 \\
\hline
\end{tabular}

Values in bold indicate cutoff $\mathrm{pH}$ values for distinguishing Ca-P species (FAP: 3.0-3.5; CFAP: 3.5-7.0; OCP: 7.0-8.1). Italics: largest differences in CFAP dissolution due to different $\mathrm{CO}_{3}$ substitution in the $\mathrm{pH}$ range 4-4.5 (MS-CFAP: $4.6 \%$; KC-CFAP: $3.4 \%$; CW-CFAP: $2.2 \% \mathrm{CO}_{3}$ ). ${ }^{\text {a }}$ Among the different CFAP phases, KC-CFAP was used to calculate the total CFAP loss. ${ }^{\mathrm{b}}$ Indicates a possible overestimate if $\mathrm{pH} 6.9$ is used for distinguishing between OCP and CFAP.

\section{Results and discussion}

\subsection{Sedimentary Ca-P speciation}

For both unspiked sediments, the slopes of curves change at $\mathrm{pH}$ values of approximately 7, 3.5 and 3 (Fig. 4a and b) due to differential dissolution of $\mathrm{Ca}-\mathrm{P}$ species, as proven by standard addition experiments (see Sect. 3.2). Octacalcium phosphate dissolved within a narrow $\mathrm{pH}$ range above $\mathrm{pH}$ 7, CFAP within a large pH interval of ca. 3.5-7 and FAP within a small $\mathrm{pH}$ range below $\mathrm{pH}$ 3.5. Due to these dissolution ranges and given species concentrations, incremental acidification-induced losses of OCP, CFAP and FAP per $\mathrm{pH}(\triangle \mathrm{OCP}, \mathrm{CFAP}, \mathrm{FAP} / \Delta \mathrm{pH})$ resulted in a steep, a less steep and a steep slope, respectively (cf. unspiked sediment in Fig. 4a and b).

Species contents of unspiked sediments are indicated by columns at the right of Fig. 4a and b. Carbonate fluorapatite in the sample from the Firth of Thames was largely elevated $(43 \%)$ based on a lower amount of FAP $(8 \%)$ and residual P $(12 \%)$ if compared to the sample from the Saigon River delta (CFAP: 25\%; FAP: $18 \%$; residual P: 20\%). Thus, species analysis showed different $\mathrm{P}$ compositions despite similar sediment properties of the two sediments compared (similar Ca-P content, reduced, slightly alkaline). However, OCP contents of both sediments were equal and with a value of $37 \%$ surprisingly high. These findings generally agree with a kinetic control of species compositions because OCP precipitates in natural systems more rapidly (days to weeks;
Bell and Black, 1970) than apatite (ten to some thousand years; Schenau, 2000; Jahnke et al., 1983; Gulbrandsen et al., 1984). Hence, more soluble species might better mirror ongoing processes, whereas sparingly soluble apatite minerals obviously reflect varying conditions over time due to slow precipitation. In accordance with such a kinetic control, OCP has been consequently proposed as a precursor for apatite formation (Gunnars et al., 2004; Krajewski et al., 1994).

The occurrence of OCP supports suggestions that authigenic apatite is formed through an OCP precursor mechanism. The precursor hypothesis agrees with earlier reported kinetic barriers but tends to contrast with the often suggested strong undersaturation of seawater with respect to CFAP. If direct nucleation of apatite is kinetically inhibited in marine environments by magnesium (Golubev et al., 1999; Gunnars et al., 2004; Martens and Harriss, 1970), the ambient water must be supersaturated with respect to a precursor to facilitate apatite formation by a less magnesium susceptible pathway. For example, in long-term incubation experiments apatite precipitated from natural brackish seawater only in case of supersaturation with respect to OCP (Gunnars et al., 2004). Under these conditions, the morphology of the precipitates (spherulites with OCP-like crystals) provided supporting evidence that OCP was a precursor to the observed formation of apatite. The liquid phase must be several times supersaturated with respect to apatite, though, in order to attain supersaturation with respect to OCP or ACP. When the calculation of the solubility of Ca-P phases under experimental conditions (Fig. 1) is modified to obtain solubilities 
for seawater of normal composition $\left(5-25^{\circ} \mathrm{C}\right.$; see e.g. Appendix in Atlas, 1975), pore-water appears to be generally undersaturated with respect to OCP. Due to widely differing solubility products (see e.g. HAP in Fig. 1) and the challenging application to multi-ion systems of high ionic strength, the uncertainty associated with such thermodynamic models is, however, relatively large. Incubations of P-spiked natural seawater on the other hand indicated that homogeneous precipitation of non-apatitic Ca-P is generally possible within some days under naturally occurring pore-water $\mathrm{P}$ concentrations (see kinetic considerations in Atlas, 1975).

Conversely, it is difficult to explain the occurrence of a highly soluble Ca-P mineral with rapid dissolution kinetics, such as OCP, when ambient water is undersaturated even with respect to a much more insoluble Ca-P species like CFAP. However, an undersaturation of bottom water with respect to marine apatite is difficult to reconcile even with the occurrence of comparatively stable ancient CFAP because the latter did not dissolve despite exposure to undersaturated conditions for millions of years (Sheldon, 1981). Accordingly, Atlas (1975) inferred that prolonged apatite persistence requires at least saturation of sediment with respect to apatite. It is even more remarkable that recent studies suggest CFAP formation in sinking particulate matter throughout the water column (Faul et al., 2005; Lyons et al., 2011) using extractions of Ruttenberg's SEDEX method (1992). Although protective coatings and microenvironments may be considered for the prevented dissolution of ancient CFAP and potentially occurring precipitation in the water column, apparent undersaturation is frequently not confirmed by field observations (Sheldon, 1981). Furthermore, a systematic comparison of P K-edge XANES fingerprints from reference materials and marine sediment particles provided direct evidence for the occurrence of OCP in marine surface sediment (Oxmann, 2014).

However, a suggested precursor pathway depends more on continuously high $\mathrm{pH}$ values and elevated DIP and calcium concentrations compared to direct CFAP nucleation. For example, Ca-P formation through an OCP precursor mechanism was detected after approximately two years of incubation in calcite-seeded brackish seawater using a DIP concentration of $500 \mu \mathrm{M}$, which is slightly higher than the range reported for interstitial water of Baltic Sea sediments (Gunnars et al., 2004). In addition, low dissolved magnesium levels may be favourable for OCP precipitation because, possibly due to less adsorption of foreign ions caused by lattice water in OCP, the growth of OCP seems to be much less but not completely uninfluenced by magnesium (e.g. Bell and Black, 1970; Johnsson and Nancollas, 1992). Yet, equilibrium calculations by means of pore water data imply that most interstitial waters of the Baltic Proper are supersaturated for long periods, at least with respect to apatite (Carman and Rahm, 1997), and thus agree with observed $P$ transformations into apatite (van Beusekom and De Jonge, 1997).
In view of the proposed but not unambiguous OCP precursor mechanism, Gunnars et al. (2004) highlighted the difficult in situ identification of authigenic apatite. However, OCP detection may pose an even larger problem because OCP is not quantifiable in sediment using any conventional method. Furthermore, OCP is not included in operationally defined fractions of common sequential extraction methods. Calcium phosphate fractions of these methods are consequently incompletely defined and those definitions may result in overestimates of other fractions and the exclusion of OCP. Possible misinterpretations might be not insubstantial in view of OCP contents detected in the present study. Overall, the proposed method offers a good opportunity to further evaluate the issues mentioned above by field or experimental studies. Results for the sediments investigated support suggestions of step-wise formation of apatite via OCP. However, further analyses of samples from other regions are required to determine spatial OCP distributions; to clarify whether successive or direct nucleation is favoured in environmental systems; and to identify factors that may facilitate or inhibit one or the other pathway at different locations.

\subsection{Solubility of calcium phosphates in sediment: verification of differential dissolution}

Results of Ca-P addition experiments (Figs. 4, 5 and 6) show mineral species successively dissolved by acidification according to their theoretical solubility, agree with thermodynamic considerations and verify the applicability of the CONVEX method. Moreover, solubility of added CFAP increased with its carbonate content, which is in line with previous studies (Chien and Black, 1976; Jahnke, 1984; LeGeros and LeGeros, 1984).

The OCP and HAP addition experiments showed that the CONVEX method can distinguish OCP from HAP in sediment. Almost complete dissolution of sedimentary and added OCP at pH 7 (cf. ST-OCP in Fig. 4a and b) verified OCP quantification by the Ca-P loss at this $\mathrm{pH}$ because added HAP was not significantly dissolved at or above $\mathrm{pH} 7$ (cf. ST-HAP in Fig. 4a and b). Addition experiments with HAP showed Ca-P loss above $\mathrm{pH} 7$ but this loss was caused by the sedimentary OCP content. The detected OCP presence only at $\mathrm{pH}$ values above ca. 7 corroborates results of soil column incubations by Bell and Black (1970), which confirmed OCP formation only in the alkaline range. Precipitation of OCP in the alkaline range also agrees with DIP concentrations in supernatant solutions of $\mathrm{pH}$ batch experiments of soils and sediments because soluble P followed the OCP isotherm (Murrmann and Peech, 1969; Oxmann et al., 2008).

The CFAP addition experiments verified that the CONVEX method can also distinguish CFAP from OCP (differential dissolution of CFAP and OCP in Fig. 4a) despite the apparently high solubility of CFAP (cf. Fig. 1; based on apparent solubility products, CFAP could be more soluble than HAP). In fact, all incubations with various CFAP minerals 


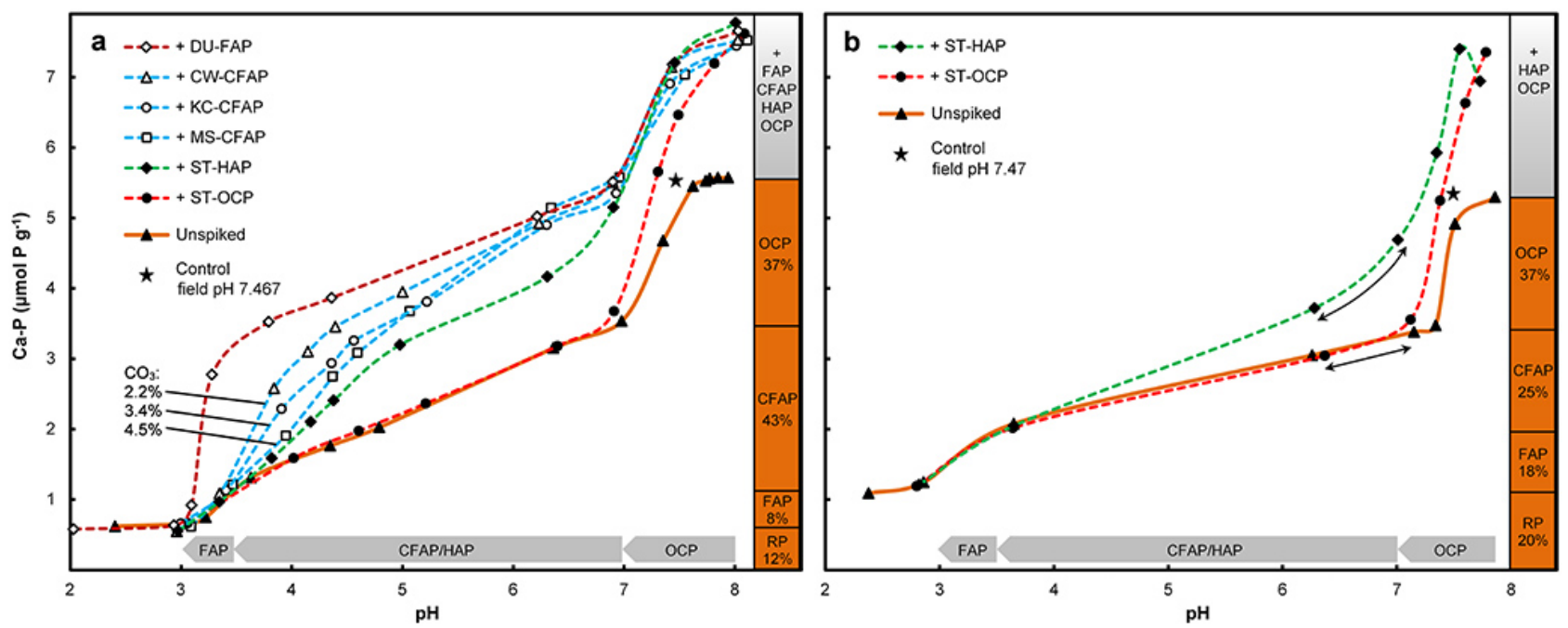

Figure 4. Differential Ca-P dissolution in sediment at varying pH as determined by subsample incubation of sediment (unspiked and with reference mineral additions) and subsequent fractionation (CONVEX method). (a) Standard addition experiments with natural and synthetic Ca-P using sediment from the Firth of Thames, New Zealand. (b) Standard addition experiments with synthetic Ca-P using sediment from the Saigon River delta, Vietnam (adapted from Oxmann et al., 2008). Columns indicate sedimentary Ca-P species composition in \% (CFAP fraction may contain some HAP; see text) and standard additions. Note the greater extent of CFAP dissolution with increasing carbonate substitution. Note the increased slope of HAP addition for both sediments in the $\mathrm{pH}$ range 6.3-6.9, which was absent for unspiked sediment (arrows for visualization in b) and other additions (cf. a) except collophane (cf. Fig. 6). Control: fractionation without prior incubation. RP: residual P. See Table 1 for abbreviations and origins of added standard materials.

revealed a reduced loss compared to HAP spiked incubations within the $\mathrm{pH}$ range 3.5-7. Therefore, natural CFAP minerals with differing carbonate content were even more stable in the sedimentary environment than synthetic HAP and consequently did not bias determined OCP contents. Lower solubility of CFAP in comparison to HAP is in agreement with reported HAP conversion into more stable CFAP or increased HAP dissolution in the water column and near-surface sediments (e.g. Burdige, 2006; Schenau and De Lange, 2000). In contrast to the separation of CFAP or HAP from OCP, quantitative discrimination between HAP and CFAP is not possible without further methodological optimization because both apatites dissolved within the same $\mathrm{pH}$ range. This finding agrees with similarities between the calculated solubilities of CFAP and HAP (Fig. 1). Yet, the presence of significant quantities of HAP can be verified because approximately half of added HAP dissolved in the $\mathrm{pH}$ range 6.3-7 (cf. ST-HAP in Fig. 4a and b) while CFAP did not. Thus, incubations with HAP additions show a steeper curve within that interval compared to unspiked sediment incubations (illustrated by curved and straight arrows in Fig. 4b, respectively) and all FAP and CFAP additions shown in Fig. 4a (cf. DU-FAP, CW-CFAP, KC-CFAP, MS-CFAP). Loss of sediment Ca-P within the range of ca. 3.5-7 was previously ascribed to HAP based on concurrent HAP dissolution during corresponding addition experiments (Oxmann et al., 2008). However, as unspiked incubations and CFAP additions did not show an increased curve slope in the $\mathrm{pH}$ range 6.3-7, contrary to HAP additions, sedimentary Ca-P loss in the $\mathrm{pH}$ range 3.5-7 was likely caused by a predominance of sediment CFAP. Yet presence of some HAP in the unspiked sediments could not be ruled out.

Standard addition with igneous FAP from Mexico (cf. DUFAP in Fig. 4a) demonstrated that Ca-P dissolution below $\mathrm{pH} 3.5$ is caused by FAP and therefore showed that the CONVEX method is able to distinguish FAP from other Ca$\mathrm{P}$ phases. All other apatites almost completely dissolved at ca. pH 3.5, whereas added FAP dissolved below this value. The observed significantly lower FAP solubility is consistent with notable differences between solubilities of laboratory synthesized FAP and CFAP detected by Jahnke (1984). Jahnke (1984) and other investigations (Chien and Black, 1976; LeGeros and LeGeros, 1984) did not only point to solubility differences between pure FAP and CFAP but also showed that increasing carbonate content strongly increases the solubility of CFAP minerals with different degrees of carbonate substitutions. Regarding the effect of crystal carbonate content on CFAP solubility, increased carbonate substitution also caused a greater extent of CFAP dissolution in the present study (cf. CW-CFAP, KC-CFAP, MS-CFAP in Fig. 4a; Table 2).

Due to this dependency on carbonate substitutions and naturally occurring carbonate traces in FAP (Table 1), separation of sedimentary FAP from CFAP could have been insufficient. Presence of both, FAP with low carbonate content and CFAP with varying extent of carbonate substitution, could 

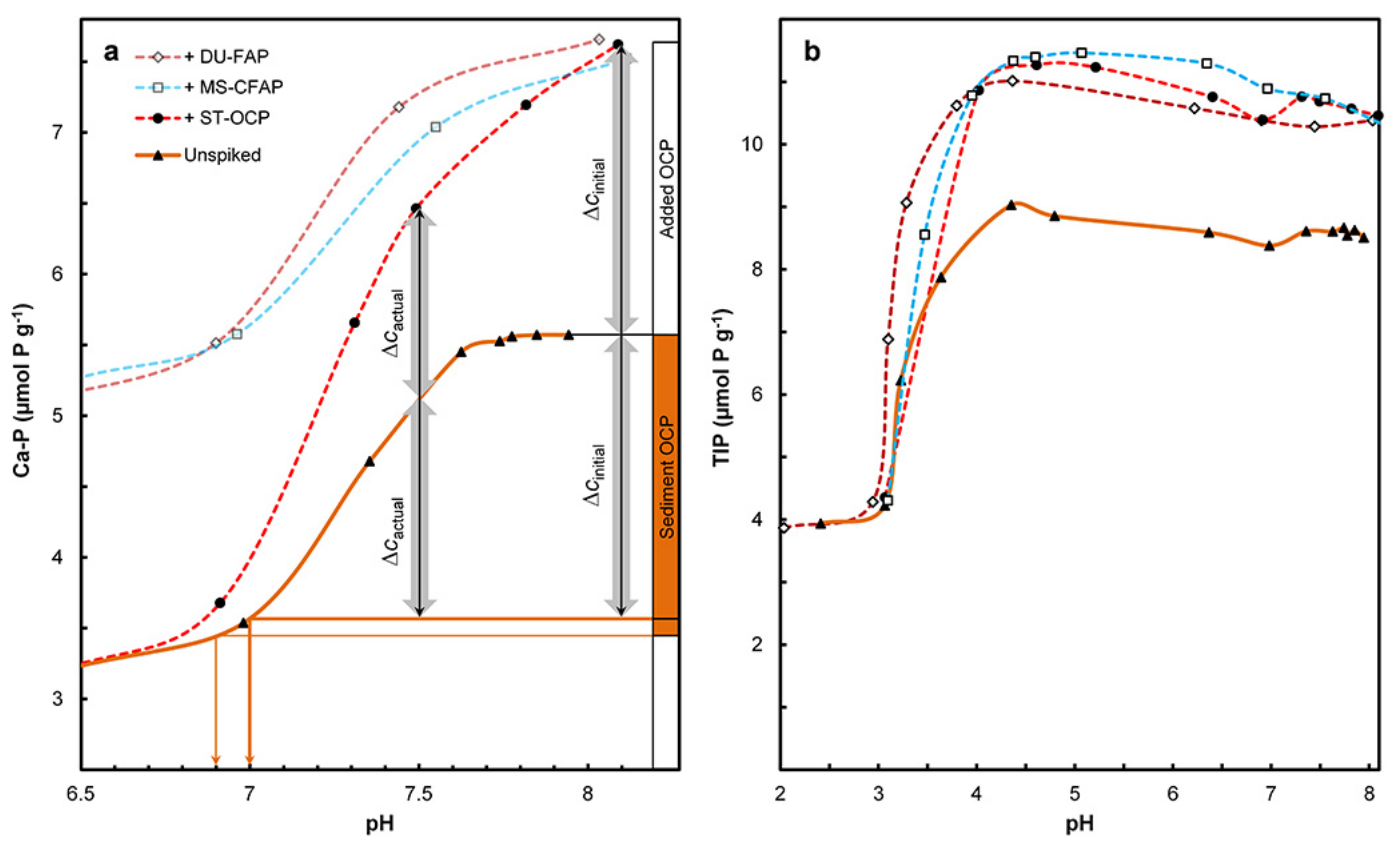

Figure 5. (a) Calculation of Ca-P species dissolution by acidification-induced losses of the Ca-P fraction as indicated for OCP. Differential OCP dissolution occurred at ca. $\mathrm{pH} 7$ (thick orange arrow) and a slightly lower $\mathrm{pH}$ (6.9; thin orange arrow) was preferable to calculate the OCP content (see text). Curves were fitted by piece-wise cubic hermite interpolating polynomial to calculate selective losses of species $\left(\Delta c_{\text {loss }}=\Delta c_{\text {initial }}-\Delta c_{\text {actual }}\right)$ at different $\mathrm{pH}$ values. Grey arrows denote initial and actual concentrations (exemplified for $\left.\mathrm{pH} 7.5\right)$ of added OCP (+ ST-OCP) and sediment OCP (unspiked). Superimposed black arrows denote corresponding concentrations of total OCP (added OCP plus sediment OCP). Calculated loss percentages for different $\mathrm{P}$ species at different $\mathrm{pH}$ values are given in Table 2. Standard addition of FAP and CFAP is shown for comparison (+ DU-FAP; + MS-CFAP; insignificant dissolution in the range of OCP dissolution). (b) Acidificationinduced changes of total inorganic $\mathrm{P}(\mathrm{TIP}=\mathrm{Ca}-\mathrm{P}+\mathrm{Al} / \mathrm{Fe}-\mathrm{P})$ for unspiked sediment and standard additions of OCP, FAP and CFAP $($ same symbols as in a).

have resulted in a significant concurrent dissolution. However, there is a pronounced slope change for unspiked sediment at ca. $\mathrm{pH} 3.5$, and the slope height in the $\mathrm{pH}$ range 3-3.5 obviously discriminates a certain amount of less soluble apatites from more soluble apatites. The ratio of slope heights is not constant for both sediments indicating that this is not an acidification-caused constant feature similarly related to all sedimentary apatites. Sediment from the Saigon River delta contained less CFAP but more FAP than sediment from the Firth of Thames. Finally, the slope change for unspiked sediment agrees with FAP and CFAP addition experiments. In conclusion, there must be certain mineral features that permit discrimination of these sedimentary apatites in the sedimentary environment in addition to the clear separation of added reference species.

However, the different mineral features that permit discrimination of FAP and CFAP are attributable to the different origins of sedimentary apatites. In contrast to authigenic CFAP, FAP is in general derived from detrital sources and delivered to marine environments by continental weathering. The $\mathrm{pH}$ at which differential dissolution of FAP and CFAP occurred during our addition experiments agrees approximately with a $\mathrm{pH}$ of 4 , at which best separation of FAP and CFAP is attained in acetate buffer solutions or dilute mineral acids (Ruttenberg, 1992). Therefore, the CONVEX method distinguishes detrital from authigenic apatite within the sediment matrix. Whether this discrimination and hence the large solubility differences between sediment FAP and CFAP were primarily attributable to different carbonate contents remained unclear. Addition experiments showed that a rather small variation in carbonate content between DU-FAP and CW-CFAP (1.0 and $2.2 \%$, respectively) coincided with large solubility differences, whereas a larger variation between CW-CFAP and MS-CFAP (2.2 and 4.5\%, respectively) corresponded to less pronounced solubility differences (cf. Table 2). As detrital FAP and authigenic CFAP can contain various impurities, which are dependent on depositional and post-depositional conditions (Guidry and MacKenzie, 2003), other factors may also contribute to their strongly differing dissolution characteristics.

\subsection{Congruency of species dissolution and possible sources of error}

Based on maximum changes in curve slopes $(\Delta c / \Delta \mathrm{pH})$ for unspiked sediment, complete dissolution of sediment OCP, CFAP and FAP was assumed to take place at $\mathrm{pH}$ values of 7.0, 3.5 and 3.0, respectively (Table 2). More than $80 \%$ of 


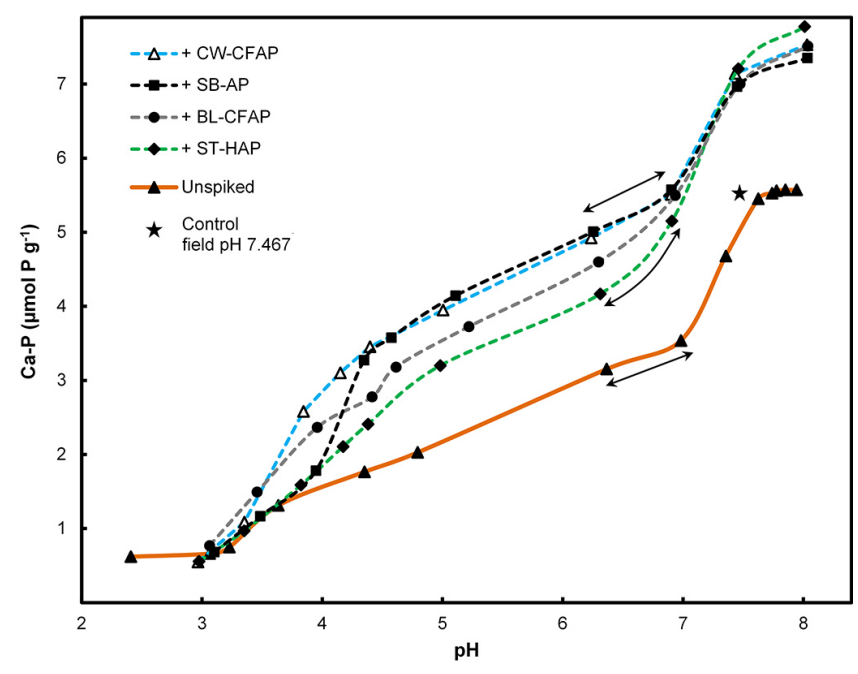

Figure 6. Differential Ca-P dissolution in sediment at varying $\mathrm{pH}$ as determined by subsample incubation of sediment (unspiked and with reference mineral additions) and subsequent fractionation (CONVEX method). Cryptocrystalline collophane (BL-CFAP) dissolved similar to HAP (ST-HAP) in the range 6.3-6.9 (see increased slope, arrows). Analysis was performed using sediment from the Firth of Thames, New Zealand. Control: fractionation without prior incubation. See Table 1 for origins of added standard materials.

added OCP dissolved at $\mathrm{pH} 7$ (value in bold in Table 2; Fig. 5a for an example of calculation). However, CFAP only sparingly dissolved at slightly lower $\mathrm{pH}$ values (see loss percentages of CFAP at $\mathrm{pH}>6.5$ ) thereby minimizing a concurrent dissolution of CFAP and OCP. Thus, a slightly lower $\mathrm{pH}$ of 6.9 was preferable to calculate OCP contents (Fig. 5a). At this $\mathrm{pH}$, the total OCP loss was approximately $100 \%$, loss of added OCP was $90 \%$, CFAP loss was lower than $5 \%$ and sediment OCP might be overestimated by $5 \%$ (Table 2).

In general more than $90 \%$ of added CFAP and FAP dissolved at $\mathrm{pH} 3.5$ and 3.0, respectively. Largest differences in CFAP dissolution due to varying carbonate inclusion were observed in the $\mathrm{pH}$ range 4 to 4.5 (Table 2, numbers in italic). Further, the dissolution of the CFAP sample with the highest degree of carbonate substitution (MS-CFAP: $4.6 \%$ ) was best correlated with the dissolution of sediment CFAP $\left(R^{2}=0.92\right.$ for the values shown in Table 2). This correlation was progressively less pronounced with decreasing carbonate substitution of the other CFAP samples (KC-CFAP: $3.4 \%, R^{2}=0.85$; CW-CFAP: $2.2 \%, R^{2}=0.73$ ) and may therefore indicate a relatively high degree of carbonate substitution of authigenic apatite of the unspiked sediment sample. However, despite the effect of carbonate substitution on CFAP dissolution, different degrees of carbonate substitution did not significantly change the dissolution range of CFAP (Fig. 4a). All in all, dissolution ranges of added FAP, CFAP and OCP were almost congruent with the three dissolution ranges of sediment Ca-P (Table 2) verifying that standards were well suited to explain these dissolution ranges.

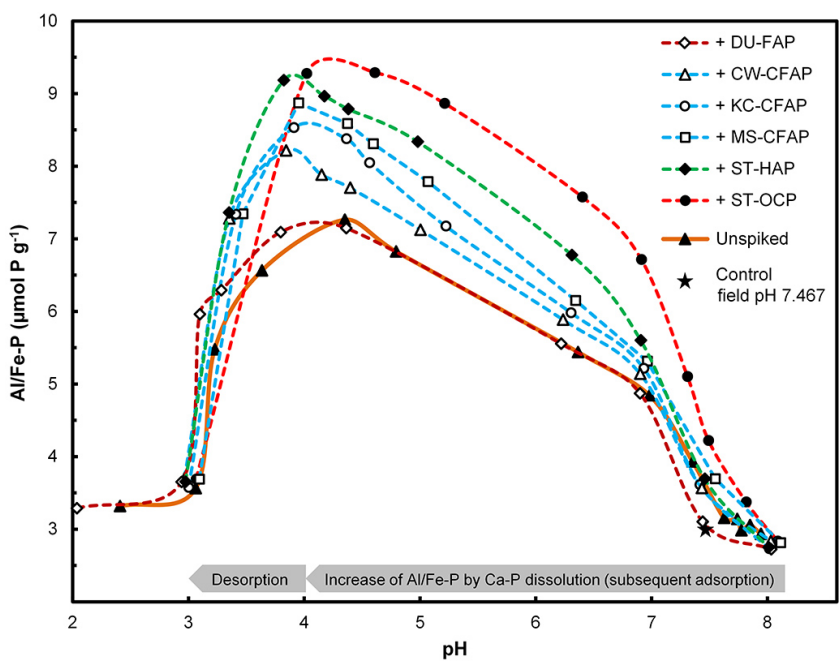

Figure 7. Increase of $\mathrm{Al} / \mathrm{Fe}-\mathrm{P}$ due to calcium phosphate dissolution (subsequent adsorption; $\mathrm{pH} 4-8$ ) and decrease of $\mathrm{Al} / \mathrm{Fe}-\mathrm{P}$ due to desorption $(\mathrm{pH}<4)$ as determined by subsample incubation of sediment (unspiked and with reference mineral additions) and subsequent fractionation (CONVEX method). Note the mirror-like reflection in the $\mathrm{pH}$ range $4-8$ when compared to Fig. 2a (except for unspiked sediment; see text). Analysis was performed using sediment from the Firth of Thames, New Zealand. Control: fractionation without prior incubation. See Table 1 for origins of added standard materials.

Regarding potential transformations, incubations at in situ $\mathrm{pH}$ did not significantly change $\mathrm{P}$ compositions. For instance, OCP was not generated by desorption of adsorbed $\mathrm{P}$ because $\mathrm{Ca}-\mathrm{P}$ and $\mathrm{Al} / \mathrm{Fe}-\mathrm{P}$ contents of controls without incubation (cf. Sect. 2.4.; Fig. 3) closely matched those of sediment incubated at in situ pH (Figs. 4 and 7). Hence, OCP did not form by $\mathrm{P}$ desorption (or any other non $\mathrm{Ca}-\mathrm{P}$ source) because total Ca-P did not increase by incubation. Furthermore, one $\mathrm{Ca}-\mathrm{P}$ species did not transform to another. If anything, one would expect extremely slow HAP formation by OCP hydrolysis (e.g. Gunnars et al., 2004) and certainly not OCP formation by apatite dissolution. None of this took place as shown by standard additions. Finally, controls without incubation were not biased by OCP formation during sequential extraction because the employed method was developed and validated to eliminate OCP precipitation (Kurmies, 1972; removal of $\mathrm{Ca}$ using three wash steps with $\mathrm{KCl} / \mathrm{EtOH}$ prior to the alkaline extraction; Fig. 3).

However, control values fit even better to $\mathrm{Ca}-\mathrm{P}$ concentrations of incubations at higher $\mathrm{pH}$ (see Ca-P contents closer to $\mathrm{pH} 8$ in Fig. $4 \mathrm{a}$ and $\mathrm{b}$ ) and were used for calculation of the most soluble species (OCP). Incubations with a final $\mathrm{pH}$ similar to field $\mathrm{pH}$ showed slight $\mathrm{Ca}-\mathrm{P}$ dissolution because the adjusted $\mathrm{pH}$ was initially somewhat lower than the final $\mathrm{pH}$ and drifted subsequently upwards. Therefore, the final $\mathrm{pH}$ did not precisely reflect the $\mathrm{pH}$ of observed loss. However, this shift is not significant because added Ca-P minerals (i) were 
subjected to the same conditions as sediment Ca-P, (ii) explained characteristic Ca-P dissolution ranges of unspiked incubations, and (iii) were measurable in the sediment matrix by differential dissolution.

\subsection{Solubility of collophane and fish bone apatite in sediment}

Collophane and fish bone specimens were also tested by standard addition experiments because various substitutions and crystal imperfections may result in increased solubility of collophane and bone apatite. Although biogenic apatite is likely an insignificant $\mathrm{P}$ sink on a global scale, it can constitute a considerable $\mathrm{P}$ fraction in some sediments. If so, biogenic apatite might bias the quantification of precursor phases due to its relatively high solubility compared to other apatites (see Schenau et al., 2000; Schenau and De Lange, 2000).

Dissolution of nanocrystalline snapper bone apatite (SBAP) was comparable to that of crystalline CFAP with lowest carbonate inclusion (CW-CFAP) at higher $\mathrm{pH}$ but matched synthetic HAP (ST-HAP) dissolution at ca. pH 4 (Fig. 6). Bone apatite is structurally similar and frequently termed as HAP but also shows considerable chemical and structural differences (Wopenka and Pasteris, 2005). This may explain why the dissolution behaviour of the bone apatite was comparable to both, crystalline CFAP and synthetic HAP. Bone apatite contains typically ca. $7 \%$ carbonate, little or a complete lack of hydroxyl substitutions and other ions may be incorporated to adjust for required properties. For example, incorporation of fluorine into apatite reduces its solubility in organisms. However, bone apatite did neither bias the determination of OCP nor the detection of detrital apatite due to absent additional Ca-P loss above pH 6.9 (loss only caused by sediment OCP) and pronounced Ca-P loss at ca. $\mathrm{pH} 4$. Likewise, OCP presence in the bone sample can be ruled out by the missing additional loss in the alkaline $\mathrm{pH}$ range. An OCP precursor during bone apatite formation has been proposed in the past but a recent publication concluded that OCP has not been detected hitherto in bone (Rey et al., 2009).

Cryptocrystalline collophane (BL-CFAP) seemed to include an apatite mixture because it dissolved in agreement with HAP, CFAP and FAP at high, medium and low $\mathrm{pH}$, respectively. Thus, incubations with collophane only showed increased dissolution comparable to HAP (increased dissolution marked by curved arrow in Fig. 6) within the $\mathrm{pH}$ range 6.3-7 among all incubation experiments. This is in agreement with expected varying collophane compositions including presence of HAP. Thus, collophane incubations indicate that significant contents of HAP are likely detectable. This conclusion additionally suggests minor contents of HAP in the unspiked sediments because they did not show increased dissolution within the $\mathrm{pH}$ range 6.3-7 (straight arrow for unspiked sediment in Fig. 6).

\subsection{Increase of $\mathrm{Al}$ / Fe-P due to calcium phosphate dissolution}

The $\mathrm{pH}$-dependent $\mathrm{Ca}-\mathrm{P}$ variations were generally reflected by $\mathrm{Al} / \mathrm{Fe}-\mathrm{P}$ contents because $\mathrm{P}$ liberated by $\mathrm{Ca}-\mathrm{P}$ dissolution was subsequently adsorbed and determined by the $\mathrm{Al} / \mathrm{Fe}-$ $\mathrm{P}$ fraction (Fig. 7). Thus, $\mathrm{Al} / \mathrm{Fe}-\mathrm{P}$ mirrored $\mathrm{Ca}-\mathrm{P}$ in the $\mathrm{pH}$ range 4-8 for each individual addition experiment with an accompanied sequence inversion among all addition experiments (cf. Figs. 7 and $4 \mathrm{a}$ ). In consequence of the almost quantitative adsorption $(\Delta \mathrm{Al} / \mathrm{Fe}-\mathrm{P} \approx \Delta \mathrm{Ca}-\mathrm{P})$, total inorganic $\mathrm{P}$ contents remained largely unchanged in the $\mathrm{pH}$ range 4-8 as shown in Fig. 5b for unspiked sediment and sediment with FAP, CFAP and OCP additions. These findings are in agreement with previous observations (Oxmann et al., 2008) and demonstrate that most $\mathrm{pH}$-induced sedimentary $\mathrm{P}$ dissolution processes cannot be observed by total inorganic $\mathrm{P}$ variations or reverse soluble $\mathrm{P}$ levels due to almost quantitative solid-phase $\mathrm{P}$ transfers. Data of $\mathrm{Al} / \mathrm{Fe}-\mathrm{P}$ and Ca-P for unspiked sediment were also mirrored in the $\mathrm{pH}$ range $4-8$. Because they always involved lowest concentrations relative to other incubations (see Fig. 5b) they naturally did not follow sequence inversion.

Below ca. $\mathrm{pH} \mathrm{4}$, less $\mathrm{P}$ was adsorbed despite large Ca$\mathrm{P}$ losses (Fig. 7). The accompanied overall loss of sediment inorganic $\mathrm{P}$ below $\mathrm{pH} 4$ (Fig. 5b) is in turn reflected by increased soluble P (see Oxmann et al., 2008). Very little free orthophosphate generated by Ca-P dissolution was adsorbed below $\mathrm{pH} 3$ resulting in an almost complete liberation of added $\mathrm{P}$ from the sedimentary environment. Thus, even the relatively low original sedimentary $\mathrm{Al} / \mathrm{Fe}-\mathrm{P}$ content $\left(3.02 \mu \mathrm{mol} \mathrm{P} \mathrm{g}^{-1}\right)$ increased just marginally $\left(3.31 \mu \mathrm{mol} \mathrm{Pg}^{-1}\right)$ due to adsorption in the strongly acidic range (Fig. 7).

\section{Conclusions}

We found that OCP dissolved above ca. pH 7 and its quantification was not biased by FAP, CFAP, HAP or biogenic apatites. Thus, the CONVEX method is able to differentiate OCP from the apatite group. Carbonate fluorapatite dissolved together with HAP in the $\mathrm{pH}$ range 3.5-7. However, HAP dissolved to a greater extent at equal $\mathrm{pH}$ and was therefore more soluble than CFAP. Below pH 3.5, FAP began to dissolve and was therefore distinguishable from other apatites, verifying that the CONVEX method also distinguishes detrital from authigenic apatites. Solubility of CFAP increased with carbonate content, particularly in the $\mathrm{pH}$ range 4-4.5. Bone apatite and collophane dissolved in a similar manner to different identified reference apatites.

Overall, this study demonstrated that the CONVEX method can be used for experimental evaluation of calcium phosphate solubilities in the sedimentary environment. Modifying the conversion procedure by adjusting the incubation 
time or varying the solution composition (e.g. different ionic strengths), could provide an understanding of dissolution kinetics and solubilities under different environmental conditions. Moreover, the method performs accurately for quantification of the most important sedimentary Ca-P species. Further analysis of sediments of different textural properties suggests that the method is robust towards differing characteristics of sample matrices (Oxmann and Schwendenmann, unpublished data). Generally, obtained results are not biased by common matrix interferences because the method of standard addition eliminates matrix effects.

The two coastal sediment samples differed in their FAP and CFAP content despite similar physical-chemical properties. However, contribution of OCP to total $\mathrm{Ca}-\mathrm{P}$ was equal for both sediments and, with a value of $37 \%$, surprisingly high. The detected OCP occurrence supports suggestions of apatite formation by an OCP precursor mechanism thereby pointing to the importance of addressing corresponding compositions of species and their geographic distributions in future studies.

Acknowledgements. We thank Michel Nieuwoudt (School of Chemical Sciences) and John Wilmshurst (School of Environment) for assistance with FTIR, Raman and XRD analyses at The University of Auckland. Special thanks to John Robertson for providing access to grinding and high precision weighing facilities at the Auckland University of Technology. Thanks also to John Rakovan (Miami University) for making the FAP specimen available and to Melissa Bowen and Charles Hyland for providing valuable comments on an earlier version of the manuscript and assisting with language editing. The project was funded by the German Research Foundation through a research fellowship granted to J. F. Oxmann under the code OX 54/2-1.

Edited by: M. Hoppema

\section{References}

Avnimelech, Y.: Phosphorus and calcium carbonate solubilities in Lake Kinneret, Limnol. Oceanogr., 28, 640-645, 1983.

Atlas, E. L.: Phosphate equilibria in seawater and interstitial waters, Ph.D. thesis, Oregon State University, Corvallis, 1975.

Atlas, E. L. and Pytkowicz, R. M.: Solubility behavior of apatites in seawater, Limnol. Oceanogr., 22, 290-300, 1977.

Baker, M. J., Blowes, D. W., and Ptacek, C. J.: Laboratory development of permeable reactive mixtures for the removal of phosphorus from onsite wastewater disposal systems, Environ. Sci. Technol., 32, 2308-2316, 1998.

Barrow, N. J., Bowden, J. W., Posner, A. M., and Quirk, J. P.: Describing the effects of electrolyte on adsorption of phosphate by a variable charge surface, Aust. J. Soil Res., 18, 395-404, 1980.

Bar-Yosef, B., Kafkafi, U., Rosenberg, R., and Sposito, G.: Phosphorus adsorption by Kaolinite and Montmorillonite: I. Effect of time, ionic strength, and pH, Soil Sci. Soc. Am. J., 52, 1580$1585,1988$.
Baturin, G. N. (Ed.): Principal features of the marine geochemistry of disseminated phosphorus, in: Developments in Sedimentology, Elsevier B. V., Amsterdam, 1981.

Bell, L. C. and Black, C. A.: Transformation of dibasic calcium phosphate dihydrate and octacalcium phosphate in slightly acid and alkaline soils, Soil Sci. Soc. Am. Proc., 34, 583-587, 1970.

Bentor, Y. K. (Ed.): Phosphorites: The unsolved problems, in: Marine Phosphorites: Geochemistry, occurrence, genesis, SEPM Special Publication, 29, 3-18, 1980.

Bray, J. T., Bricker, O. P., and Troup, B. N.: Phosphate in interstitial waters of anoxic sediments: Oxidation effects during sampling procedure, Science, 180, 1362-1364, 1973.

Burdige, D. J. (Ed.): Geochemistry of marine sediments, Princeton University Press, New Jersey/Oxfordshire, 2006.

Carman, R. and Rahm, L.: Early diagenesis and chemical characteristics of interstitial water and sediments in the deep deposition bottoms of the Baltic Proper, J. Sea Res., 37, 25-47, 1997.

Chen, Y. S. R., Butler, J. N., and Stumm, W.: Kinetic study of phosphate reaction with aluminum oxide and kaolinite, Environ. Sci. Technol., 7, 327-332, 1973.

Chien, S. H. and Black, C. A.: Free energy of formation of carbonate apatites in some phosphate rocks, Soil Sci. Soc. Am. J., 40, 234 239, 1976.

Christoffersen, M. R., Christoffersen, J., and Kibalczyc, W.: Apparent solubilities of 2 amorphous calcium phosphates and of octacalcium phosphate in the temperature-range $30-42{ }^{\circ} \mathrm{C}$, J. Cryst. Growth, 106, 349-354, 1990.

Crosby, C. H. and Bailey, J.: The role of microbes in the formation of modern and ancient phosphatic mineral deposits, Front. Microbiol., 3, 241, doi:10.3389/fmicb.2012.00241, 2012.

Daesslé, L. W., Camacho-Ibar, V. F., Carriquiry, J. D., and OrtizHernández, M. C.: The geochemistry and sources of metals and phosphorus in the recent sediments from the Northern Gulf of California, Cont. Shelf Res., 24, 2093-2106, 2004.

Eaton, J. W., Bateman, D., and Hauberg, S.: GNU Octave Manual Version 3, Network Theory Ltd, UK, 2008.

Einsele, W.: Über die Beziehungen des Eisenkreislaufs zum Phosphatkreislauf im eutrophen See, Arch. Hydrobiol., 29, 664-686, 1936.

Emerson, S. and Widmer, G.: Early diagenesis in anaerobic lake sediments II. Thermodynamic and kinetic factors controlling the formation of iron phosphate, Geochim. Cosmochim. Ac., 42, 1316-1316, 1978.

Faul, K. L., Paytan, A., and Delaney, M. L.: Phosphorus distribution in sinking oceanic particulate matter, Mar. Chem., 97, 307-333, 2005.

Featherstone, J. D. B., Pearson, S., and LeGeros, R. Z.: An infrared method for quantification of carbonate in carbonated apatites, Caries Res., 18, 63-66, 1984.

Gaudette, H. E. and Lyons, W. B.: Phosphate geochemistry in nearshore carbonate sediments: a suggestion of apatite formation, SEPM Special Publication, 29, 215-225, 1980.

Golterman, H. L.: Phosphate release from anoxic sediments or "What did Mortimer really write?", Hydrobiologia, 450, 99-106, 2001.

Golubev, S. V., Pokrovsky, O. S., and Savenko, V. S.: Unseeded precipitation of calcium and magnesium phosphates from modified seawater solutions, J. Cryst. Growth, 205, 354-360, 1999. 
Guidry, M. W. and MacKenzie, F. T.: Experimental study of igneous and sedimentary apatite dissolution: Control of $\mathrm{pH}$, distance from equilibrium, and temperature on dissolution rates, Geochim. Cosmochim. Ac., 67, 2949-2963, 2003.

Gulbrandsen, R. A., Roberson, C. E., and Neil, S. T.: Time and the crystallization of apatite in seawater, Geochim. Cosmochim. Ac., 48, 213-218, 1984.

Gunnars, A., Blomqvist, S., and Martinsson, C.: Inorganic formation of apatite in brackish seawater from the Baltic Sea: an experimental approach, Mar. Chem., 91, 15-26, 2004.

Hedley, M. J., Stewart, J. W. B., and Chauhan, B. S.: Changes in inorganic and organic soil phosphorus fractions by cultivation practices and by laboratory incubations, Soil Sci. Soc. Am. J., 46, 970-976, 1982.

Hutchison, K. J. and Hesterberg, D.: Dissolution of phosphate in a phosphorus-enriched ultisol as affected by microbial reduction, J. Environ. Qual., 33, 1793-1802, 2004.

Jahnke, R. A.: The synthesis and solubility of carbonate fluorapatite, Am. J. Sci., 284, 58-78, 1984.

Jahnke, R. A., Emerson, S. R., Roe, K. K., and Burnett, W. C.: The present day formation of apatite in Mexican continental margin sediments, Geochim. Cosmochim. Ac., 47, 259-266, 1983.

Johnsson, M. S. and Nancollas, G. H.: The role of brushite and octacalcium phosphate in apatite formation, Crit. Rev. Oral Biol. Med., 3, 61-82, 1992.

Jourabchi, P., Van Cappellen, P., and Regnier, P.: Quantitative interpretation of $\mathrm{pH}$ distributions in aquatic sediments: A reactiontransport modeling approach, Am. J. Sci., 305, 919-956, 2005.

Kazakov, A. V.: The phosphorite facies and the genesis of phosphorites, in: Geological investigations of agricultural ores, Transactions of the Science Institute of Fertilizers and InsectoFungicides, Leningrad, 95-113, 1937.

Krajewski, K. P., Van Cappellen, P., Trichet, J., Kuhn, O., Lucas, J., Martinalgarra, A., Prevot, L., Tewari, V. C., Gaspar, L., Knight, R. I., and Lamboy, M.: Biological processes and apatite formation in sedimentary environments, Eclog. Geol. Helvet., 87, 701745, 1994.

Kruse, J., Negassa, W., Appathurai, N., Zuin, L., and Leinweber, P.: Phosphorus speciation in sequentially extracted agro-industrial by-products: Evidence from X-ray absorption near edge structure spectroscopy, J. Environ. Qual., 39, 2179-2184, 2010.

Kuo, S.: Phosphorus, Methods of Soil Analysis: Chemical Methods. Part 3, WASA and SSSA, Madison, 869-919, 1996.

Kurmies, B.: Zur Fraktionierung der Bodenphosphate, Die Phosphorsäure, 29, 118-149, 1972.

LeGeros, R. Z. and LeGeros, J. P.: Phosphate minerals in human tissues, Phosphate minerals, Springer Verlag, Berlin, 1984.

Lindsay, W. L., Vlek, P. L. G., and Chien, S. H.: Phosphate minerals, in: Minerals in soil environments, edited by: Dixon, J. B. and Weed, S. B., Soil Sci. Soc. Am., Madison, 1089-1130, 1989.

Lyons, G., Benitez-Nelson, C. R., and Thunell, R. C.: Phosphorus composition of sinking particles in the Guaymas Basin, Guf of California, Limnol. Oceanogr., 56, 1093-1105, 2011.

Martens, C. S. and Harriss, R. C.: Inhibition of apatite precipitation in the marine environment by magnesium ions, Geochim. Cosmochim. Ac., 84, 621-625, 1970.

Morse, J. W. and Casey, W. H.: Ostwald processes and mineral paragenesis in sediments, Am. J. Sci., 288, 537-560, 1988.
Morse, J. W. and Cook, N.: The distribution and form of phosphorus in North Atlantic Ocean deep-sea and continental slope sediments, Limnol. Oceanogr., 23, 825-830, 1978.

Mortimer, C. H.: The exchange of dissolved substances between mud and water in lakes, J. Ecol., 29, 280-329, 1941.

Mortimer, C. H.: Chemical exchanges between sediments and water in Great Lakes - Speculations on probable regulatory mechanisms, Limnol. Oceanogr., 16, 387-404, 1971.

Murphy, J. and Riley, J. P.: A modified single solution method for the determination of phosphate in natural waters, Anal. Chim. Ac., 27, 31-36, 1962.

Murrmann, R. P. and Peech, M.: Effect of pH on labile and soluble phosphate in soils, Soil. Sci. Soc. Am. Proc., 33, 205-210, 1969.

Naidu, R., Syersy, J. K., Tillman, R. W., and Kirkman, J. H.: Effect of liming on phosphate sorption by acid soils, Eur. J. Soil Sci., 41, 165-175, 1990.

Nancollas, G. H., LoRe, M., Perez, L., Richardson, C., and Zawacki, S. J.: Mineral phases of calcium phosphate, Anat. Rec., 224, 234 241, 1989.

Oh, Y.-M., Hesterberg, D. L., and Nelson, P. V.: Comparison of phosphate adsorption on clay minerals for soilless root media, Commun. Soil Sci. Plan., 30, 747-756, 1999.

Oxmann, J. F.: Technical Note: An X-ray absorption method for the identification of calcium phosphate species using peak-height ratios, Biogeosciences, 11, 2169-2183, doi:10.5194/bg-11-21692014, 2014.

Oxmann, J. F., Pham, Q. H., and Lara, R. J.: Quantification of individual phosphorus species in sediment: A sequential conversion and extraction method, Eur. J. Soil Sci., 59, 1177-1190, 2008.

Oxmann, J. F., Pham, Q. H., Schwendenmann, L., Stellman, J. M., and Lara, R. J.: Mangrove reforestation in Vietnam: The effect of sediment physicochemical properties on nutrient cycling, Plant Soil, 326, 225-241, 2010.

Parfitt, R. L., Atkinson, R. J., and Smart, R. S. C.: The mechanism of phosphate fixation by iron oxides, Soil Sci. Soc. Am. J., 39, 837-841, 1975.

Parrish, J. T., Zeigler, A. M., Scotese, C. R., Humphreville, R. G., and Kirschvink, J. K.: Proterozoic and Cambrian phosphorites - specialist studies, Early Cambrian palaeogeography, palaeoceanography and phosphorites, in: Phosphate deposits of the world. Volume I, Proterozoic and Cambrian phosphorites, edited by: Cook, P. J. and Shergold, J. H., Cambridge University Press, Cambridge, 280-294, 1986.

Perrone, J., Fourest, B., and Giffaut, E.: Surface characterization of synthetic and mineral carbonate fluoroapatites, J. Colloid Interf. Sci., 249, 441-452, 2002.

Pevear, D. R.: The estuarine formation of United States Atlantic Coastal Plain phosphorite, Econ. Geol., 61, 251-256, 1966.

Puigdomenech, I.: Windows software for the graphical presentation of chemical speciation, in: 219th ACS National Meeting, Abstracts of Papers, Vol. 1, Am. Chem. Soc., Washington, DC, 2000.

Rey, C., Combes, C., Drouet, C., and Glimcher, M. J.: Bone mineral: update on chemical composition and structure, Osteoporosis Int., 20, 1013-1021, 2009.

Ruttenberg, K. C.: Development of a sequential extraction method for different forms of phosphorus in marine sediments, Limnol. Oceanogr., 37, 1460-1482, 1992. 
Ruttenberg, K. C. and Berner, R. A.: Authigenic apatite formation and burial in sediments from non-upwelling continental margin environments, Geochim. Cosmochim. Ac., 57, 991-1007, 1993.

Schenau, S. J. and De Lange, G. J.: A novel chemical method to quantify fish debris in marine sediments, Limnol. Oceanogr., 45, 963-971, 2000.

Schenau, S. J., Slomp, C. P., and De Lange, G. J.: Phosphogenesis and active phosphorite formation in sediments from the Arabian Sea oxygen minimum zone, Mar. Geol., 169, 1-20, 2000.

Schulz, H. N. and Schulz, H. D.: Large sulfur bacteria and the formation of phosphorite, Science, 307, 416-418, 2005.

Sheldon, R. P.: Ancient marine phosphorites, Annu. Rev. Earth Pl. Sc., 9, 251-284, 1981.

Spiteri, C., Cappellen, P. V., and Regnier, P.: Surface complexation effects on phosphate adsorption to ferric iron oxyhydroxides along $\mathrm{pH}$ and salinity gradients in estuaries and coastal aquifers, Geochim. Cosmochim. Ac., 72, 3431-3445, 2008.
Tribble, J. S., Arvidson, R. S., Lane III, M., and Mackenzie, F. T.: Crystal chemistry, and thermodynamic and kinetic properties of calcite, dolomite, apatite, and biogenic silica: applications to petrologic problems, Sediment. Geol., 95, 11-37, 1995.

Tyler, G.: Phosphorus fractions in grassland soils, Chemosphere, 48, 343-349, 2002.

Van Beusekom, J. E. E. and De Jonge, V. N.: Transformation of phosphorus in the Wadden Sea: Apatite formation, Deutsche Hydrographische Zeitschrift, 49, 297-305, 1997.

Van Cappellen, P. and Berner, R. A.: A mathematical model for the early diagenesis of phosphorus and fluorine in marine sediments; apatite precipitation, Am. J. Sci., 288, 289-333, 1988.

Wopenka, B. and Pasteris, J. D.: A mineralogical perspective on the apatite in bone, Mater. Sci. Eng., 25, 131-143, 2005. 